Article

\title{
Exploring Additive, Synergistic or Antagonistic Effects of Natural Plant Extracts on In Vitro Beef Feedlot-Type Rumen Microbial Fermentation Conditions
}

\author{
Ignacio Fandiño ${ }^{1,+}$, Gonzalo Fernandez-Turren ${ }^{2}$, Alfred Ferret ${ }^{1}$, Diego Moya ${ }^{1}$, \\ Lorena Castillejos ${ }^{1} \mathbb{D}$ and Sergio Calsamiglia ${ }^{1, *}$ \\ 1 Departamento de Ciència Animal i dels Aliments, Universitat Autònoma de Barcelona, Servicio de Nutrición \\ y Bienestar Animal (SNiBA), 08193 Bellaterra, Spain; alfred.ferret@uab.cat (A.F.); \\ diego.moya@usask.ca (D.M.); Lorena.castillejos@uab.cat (L.C.) \\ 2 Departamento de Producción Animal, Instituto de Producción Animal, Facultad de Veterinaria, Universidad \\ de la República, Ruta 1 km 42, CP 80100 San José, Uruguay; gonzalofernandezt@gmail.com \\ * Correspondence: sergio.calsamiglia@uab.cat; Tel.:+34-9358-1495; Fax: +34-935-811-494 \\ + Deceased.
}

Received: 22 December 2019; Accepted: 14 January 2020; Published: 20 January 2020

check for updates

Simple Summary: Essential oils (EO) can be used as natural alternatives to in-feed antibiotics. Most $\mathrm{EO}$ products in the market are based on a combination of $\mathrm{EO}$ or their active molecules but prove of additivity or synergy is lacking. The effect of six EO (tea tree oil-TeTr, oregano oil-Ore, clove bud oil—Clo, thyme oil—Thy, rosemary oil—Ros and sage oil—Sag) and different mixes on in vitro microbial fermentation profile of a feedlot beef cattle type fermentation were evaluated for their additive, synergistic or antagonistic effects. Mixing TeTr with Thy, Ore or Thy + Ore modified rumen microbial fermentation profile, but the size of the effect was similar to that obtained with TeTr alone, suggesting that the effects were not additive. When Thy, Ore or Thy + Ore were mixed with Clo, most effects on rumen fermentation profile disappeared even when TeTr was part of the mix, suggesting an antagonistic interaction of Clo with Thy and Ore. Results do not support the hypothesis of additivity among the EO tested, and antagonistic effects may occur among some of them, at least in a low $\mathrm{pH}$, beef-type fermentation conditions.

\begin{abstract}
Six Essential oils (EO) (tea tree oil-TeTr, oregano oil-Ore, clove bud oil-Clo, thyme oil-Thy, rosemary oil-Ros, and sage oil-Sag) in Experiment 1; and different combinations of selected oils in Experiment 2, were evaluate at four doses in an in vitro microbial fermentation system using ruminal fluid from beef cattle fed a 10:90 straw: Concentrate diet. In Experiment 1, TeTr, Ore, Clo and Thy improved rumen fermentation profile in a direction consistent with better feed utilization. In Experiment 2, TeTr mixed with Thy, Ore, Thy + Ore or Clo at 200 and $400 \mathrm{mg} / \mathrm{L}$ increased the molar proportion of propionate and decreased that of acetate, and the acetate to propionate ratio. However, the size of the effect was similar to that obtained with TeTr alone, suggesting that effects were not additive. When Thy, Ore or Thy + Ore where mixed with Clo, most effects on rumen fermentation profile disappeared, suggesting an antagonistic interaction of Clo with Thy and Ore. Results do not support the hypothesis of additivity among the EO tested, and antagonistic effects of Clo mixed with Thy or Ore were demonstrated at least in a low $\mathrm{pH}$, beef-type fermentation conditions.
\end{abstract}

Keywords: essential oils; rumen microbial fermentation; synergies 


\section{Introduction}

Essential oils (EO) are aromatic oily liquids obtained from plants that can be used as natural alternatives to in-feed antibiotics [1,2]. Many different plant EO and their active components have been tested for their effects on ruminal microbial fermentation profile [3-5]. Because of the diverse mechanisms of action and effects, Calsamiglia et al. [1] suggested that the wise selection and combination of different EO may enhance ruminal fermentation. When combinations of EO are used, the effect may be additive, synergistic or antagonistic. Most EO products for ruminants in the market are based on combination of different EO or their active molecules (i.e., CRINA-Ruminants ${ }^{\circledR}$, DSM, Switzerland; AGOLIN $^{\circledR}$, Agolin Sa, Switzerland, XTRACT ${ }^{\circledR}$, Pancosma, Switzerland), but proof of additivity or synergy is lacking. Some studies attributed additive and synergistic effects to phenolic and alcohol compounds. In general, compounds with similar structures exhibit additive rather than synergistic effects. Antagonistic effects have been attributed to the interaction between non-oxygenated and oxygenated monoterpene hydrocarbons [6]. All these interactions have been demonstrated in cosmetic and food industry [6-8]. However, it is surprising that no studies have been specifically designed to prove additivity or synergies of different EO on rumen microbial fermentation. The mechanism of action of most EO is mediated through their interaction with the cell membrane, and this interaction is dependent on the fermentation conditions like the source of rumen fluid, the substrate of fermentation and $\mathrm{pH}[1,5]$. The additive, synergistic or antagonistic effects in EO mixes may also be dependent on these fermentation conditions. While most research in vitro has been conducted using rumen fluid from dairy cattle, forage as a main fermentation substrate and $\mathrm{pH}$ above 6.5, research in high concentrate feedlot-type beef fermentation conditions is more limited.

We hypothesize that the combination of different EO, in particular simple phenolic-type molecules of the family of monoterpenoids and phenylpropanes, will result in additive or synergistic effects. The objective of the present study was to evaluate the effects of different doses of six EO and the additive, synergistic or antagonistic effects of their combinations under feedlot beet-type ruminal microbial fermentation conditions in vitro.

\section{Materials and Methods}

\subsection{Experimental Protocol and Treatments}

The research protocol was approved by Campus Laboratory Animal Care Committee of the Universitat Autónoma of Barcelona (Spain) (reference CEAAH 00604). The effects of six EO and their combinations were evaluated in an in vitro batch fermentation system. Rumen fluid was obtained from four beef heifers fed a 10:90 barley straw:concentrate diet (161 g/kgcrude protein, $321 \mathrm{~g} / \mathrm{kg}$ neutral detergent fiber, $168 \mathrm{~g} / \mathrm{kg}$ acid detergent fiber on a dry matter basis) designed to meet or exceed nutrient recommendations [9] of growing beef cattle. The concentrate consisted of (DM basis) ground barley grain $(444 \mathrm{~g} / \mathrm{kg})$, corn gluten feed $(155 \mathrm{~g} / \mathrm{kg})$, ground corn grain (133 g/kg), soybean meal (72 g/kg), sunflower meal (72 g/kg), ground wheat grain $(69 \mathrm{~g} / \mathrm{kg})$, palm kernel (52 g/kg), vitamin A (4600 $\mathrm{IU} / \mathrm{kg})$, vitamin D (450 IU/ $\mathrm{kg})$, vitamin E (7.5 mg/kg), zinc $(10.5 \mathrm{mg} / \mathrm{kg})$, iron $(6 \mathrm{mg} / \mathrm{kg})$, manganese $(1.2 \mathrm{mg} / \mathrm{kg})$, copper $(0.75 \mathrm{mg} / \mathrm{kg})$, cobalt $(0.15 \mathrm{mg} / \mathrm{kg})$, iodine $(0.11 \mathrm{mg} / \mathrm{kg})$ and selenium $(0.08 \mathrm{mg} / \mathrm{kg})$. Rumen fluid was strained through two layers of cheesecloth and mixed in a 1:1 proportion with a phosphate-bicarbonate buffer [10]. The $\mathrm{pH}$ of the buffered fluid was adjusted to 6.20 with hydrochloric acid. Incubations were conducted in a $75 \mathrm{ml}$ tubes containing $50 \mathrm{ml}$ of the diluted rumen fluid and 0.5 $\mathrm{g}$ of the same diet fed to the donor animals. The diet was ground through a $2 \mathrm{~mm}$ screen, and each tube was gassed with $\mathrm{CO}_{2}$ before sealing with rubber corks with a gas release valve. Incubations were conducted in a water bath at $39^{\circ} \mathrm{C}$ for $24 \mathrm{~h}$ in two consecutive periods with triplicates within period.

In Experiment 1, four doses of different $\mathrm{EO}(10,50,200$ and $400 \mathrm{mg} / \mathrm{L}$ of the culture fluid) were evaluated. Most EO have shown to be effective at doses around 200-400 mg/L [1,3,5]. Doses were selected based on this evidence and at lower doses to show potential additivity and synergies of effects. Treatments were a negative control without EO (CTR), a positive control with Monensin at 
10 mg/L (M5273 Sigma-Aldrich Chemical, St Louis, MO, USA) and six different phenolic-derived monoterpene or phenylpropane EO, of which two were oxygenated and four non-oxygenated: 1) Tea tree oil (Melaleuca alternifolia; TeTr; containing 42\% terpinen-4-ol as active component), Oregano oil (Origanum vulgare; Ore; containing 53\% carvacrol as active components), Clove bud oil (Syzygium aromaticum; Clo; containing $82 \%$ eugenol as main active component), Thyme oil (Thymus vulgaris; Thy; containing $47 \%$ thymol as main active component), Rosemary oil (Rosmarinus officinalis; Ros; containing 61\% 1,8-cineole as main active component) and Sage oil (Salvia officinalis; Sag; containing 65\% thujone as main active component). In Experiment 2, four EO selected from Experiment 1 (TeTr, Thy, Ore and Clo) were used in 13 different combinations at four concentrations (10, 50, 200 and $400 \mathrm{mg} / \mathrm{L}$ of the culture fluid; Table 1) to test additive, synergistic or antagonist effects.

Table 1. Treatments and combination of essential oils evaluated in in vitro fermentation.

\begin{tabular}{ccccc}
\hline \multirow{2}{*}{ Treatment Number } & \multicolumn{4}{c}{ Combination of Essential Oils (\%) } \\
\cline { 2 - 5 } & Tea-tree & Clove Bud & Thyme & Oregano \\
\hline 1 & 75 & 25 & - & - \\
2 & 75 & - & 25 & - \\
3 & 75 & - & - & 25 \\
4 & 50 & 50 & - & - \\
5 & 50 & - & 25 & 25 \\
6 & 50 & 25 & 25 & - \\
7 & 50 & 25 & - & 25 \\
8 & 25 & 50 & 25 & - \\
9 & 25 & 50 & - & 25 \\
10 & 25 & 75 & - & - \\
11 & - & 75 & 25 & - \\
12 & - & 75 & - & 25 \\
13 & - & 50 & 25 & 25 \\
\hline
\end{tabular}

\subsection{Sample Collection and Chemical Analyses}

After $24 \mathrm{~h}$, the fermented fluid $\mathrm{pH}$ was measured immediately (Model 507; Crison Instruments, Alella, Barcelona, Spain) and liquid samples were withdrawn from each tube to analyze ammonia-N and volatile fatty acid (VFA) concentrations. Samples for ammonia-N analysis ( $5 \mathrm{~mL}$ of fermentation fluid preserved with $1 \mathrm{~mL}$ of a $50 \mathrm{~g} / \mathrm{L}$ orthophosphoric acid solution) were centrifuged at $15,000 \times \mathrm{g}$ for $15 \mathrm{~min}$ at $4{ }^{\circ} \mathrm{C}$, and the supernatant was analyzed for ammonia-N by colorimetry [11]. Samples for VFA analysis were prepared as described by Jouany [12]. Samples of fermented fluid (5 mL) were preserved with $1 \mathrm{~mL}$ of a solution made of $2 \mathrm{~g} / \mathrm{L}$ of mercuric chloride, $35 \mathrm{~g} / \mathrm{L}$ orthophosphoric acid and $2 \mathrm{~g} / \mathrm{L}$ of 4-methylvaleric acid as an internal standard, and frozen. After thawing, samples were centrifuged at $3000 \times g$ for $30 \mathrm{~min}$, and the supernatant fraction was analyzed by gas chromatography (Model 6890; Hewlett Packard, Palo Alto, CA, USA) using a polyethylene glycol nitroterephthalic acid-treated capillary column (BP21; SGE, Europe Ltd., Buckinghamshire, UK) at $275^{\circ} \mathrm{C}$ in the injector and a gas flow rate of $29.9 \mathrm{~mL} / \mathrm{min}$.

\subsection{Statistical Analyses}

Results of the batch fermentation experiment were analyzed as a randomized complete block design using the PROC MIXED procedure (SAS, version 9.4, SAS Institute Inc., Cary, NC, USA), where the essential oils or mixes were the fixed effect and the period was considered a random effect. Because the objective was to identify the lowest dose of EO at which effects were observed, the Dunnett test was used to identify significant differences $(p<0.05)$. When required, the synergistic, additive or antagonistic effects of mixes were evaluated comparing the relative response of the mixes vs. the corresponding effects of the main essential oil using a paired t-test at a significant level of $p<0.05$. 


\section{Results}

Because of the large number of treatments tested, two runs in Experiment 1, and six runs in Experiment 2 were conducted. To account for possible run-to-run variation, a negative (no additive) control was used, and results are reported as percent change compared with this negative control (Tables 2 and 3).

\subsection{Experiment 1 (Individual Essential Oils)}

Results from Experiment 1 are shown in Table 2. Monensin was used as a positive control and always increased $(p<0.05)$ the proportion of propionate and decreased $(p<0.05)$ the molar proportion of acetate and the acetate to propionate (A:P) ratio. In most cases, monensin also reduced the molar proportion of butyrate and brach-chain VFA (BCVFA), and the concentration of ammonia-N when compared with control.

None of the EO treatments affected rumen fermentation profile at $10 \mathrm{mg} / \mathrm{L}$ compared with control. Tea tree oil at 50 and $200 \mathrm{mg} / \mathrm{L}$ decreased $(p<0.05)$ the molar proportion of acetate $(-9$ to $-15 \%)$ and the A:P ratio $(-22$ to $-36 \%)$, and increased $(p<0.05)$ the molar proportion of propionate $(+18$ to $+34 \%)$ and butyrate ( +14 to $+21 \%)$. At $400 \mathrm{mg} / \mathrm{L} \mathrm{TeTr}$ only increased $(p<0.05)$ the molar proportion of butyrate $(+14 \%)$ compared with control. Oregano oil at 50 and $200 \mathrm{mg} / \mathrm{L}$ decreased $(p<0.05)$ the molar proportion of acetate ( -9 to $-11 \%)$ and the A:P ratio $(-26$ to $-9 \%)$ and increased $(p<0.05)$ the molar proportion of propionate $(+24$ to $+25 \%)$ and the molar proportion of butyrate $(+12$ to $+16 \%)$, but at $400 \mathrm{mg} / \mathrm{L}$ increased $(p<0.05)$ the molar proportion of butyrate $(+17 \%)$ and the $\mathrm{pH}(+2 \%)$ compared with control. Clove bud oil at $50 \mathrm{mg} / \mathrm{L}$ had no effects on rumen microbial fermentation, but at 200 and $400 \mathrm{mg} / \mathrm{L}$ increased $(p<0.05)$ the molar proportion of butyrate $(+10$ to $+18 \%)$, and at $400 \mathrm{mg} / \mathrm{L}$, decreased $(p<0.05)$ the molar proportion of propionate $(-13 \%)$, and increased $(p<0.05)$ the A:P ratio $(+15 \%)$ and the $\mathrm{pH}(+2 \%)$ compared with control. Thyme oil at 50 and 200 decreased $(p<0.05)$ the molar proportion of acetate $(-6 \%)$ and the A:P ratio $(-25$ to $-28 \%)$, and increased $(p<0.05)$ the molar proportion of propionate $(+24$ to $+30 \%)$. At 200 and $400 \mathrm{mg} / \mathrm{L}$ Thy decreased $(p<0.05)$ the molar proportion of butyrate $(-15$ to $-21 \%)$, but only at $400 \mathrm{mg} / \mathrm{L}$ decreased $(p<0.05)$ the total VFA concentration $(-4 \%)$, the BCVFA concentration $(-16 \%)$ and the concentration of ammonia-N $(-17 \%)$, and increased $(p<0.05)$ the molar proportion of acetate $(+5 \%)$. Rosemary oil at $50 \mathrm{mg} / \mathrm{L}$ had no effect on rumen microbial fermentation, but at 200 and $400 \mathrm{mg} / \mathrm{L}$ decreased $(p<0.05)$ the molar proportion of butyrate $(-14$ to $-19 \%)$ and at $400 \mathrm{mg} / \mathrm{L}$ increased $(p<0.05)$ the molar proportion of acetate $(-4 \%)$ and decreased the total VFA concentration (-5\%) compared with control. Sage oil at $50 \mathrm{mg} / \mathrm{L} \mathrm{had} \mathrm{no}$ effect on rumen microbial fermentation, but at $200 \mathrm{mg} / \mathrm{L}$ decreased $(p<0.05)$ the molar proportion of butyrate $(-17 \%)$ and at $400 \mathrm{mg} / \mathrm{L}$, increased $(p<0.05)$ the molar proportion of propionate $(+12 \%)$, reduced $(p<0.05)$ the A:P ratio $(-13 \%)$ and the concentration of ammonia- $\mathrm{N}(-16 \%)$, and tended to reduce $(p<0.10)$ the total VFA concentration $(-4 \%)$ compared with control. 
Table 2. Effect of Tea Tree (TeTr), Oregano (Ore), Clove bud (Clo), Thyme (Thy), Rosmarinus officinalis (Ros), Sage oil (Sag) and Monensin (MON) on pH, ammonia-N and total and individual VFA concentrations in vitro fermentation of 10:90 forage to concentrate diet $(n=6)$.

\begin{tabular}{|c|c|c|c|c|c|c|c|c|c|}
\hline Treatment & $\mathrm{pH}$ & $\mathrm{NH}_{3}, \mathrm{mg} / \mathrm{dL}$ & Total VFA, mM & Acetate, \% & Propionate, $\%$ & Butyrate, \% & Valerate, $\%$ & BCVFA $^{2}, \mathrm{mM}$ & $\mathrm{A}: \mathrm{P}^{3}$ \\
\hline CTR & 5.33 & 13.2 & 133.2 & 61.8 & 18.8 & 13.4 & 3.46 & 3.47 & 3.28 \\
\hline $\operatorname{TeTr} 10^{a}$ & 5.32 & 13.2 & 132.7 & 61.3 & 18.1 & 14.4 & 3.53 & 3.41 & 3.38 \\
\hline $\operatorname{Te} \operatorname{Tr} 50^{\mathrm{b}}$ & 5.33 & 13.2 & 129.0 & $56.5^{*}$ & 22.2 * & 15.2 * & 3.56 & 3.26 & $2.55^{*}$ \\
\hline $\operatorname{Te} \operatorname{Tr} 200^{c}$ & 5.33 & 13.6 & 127.0 & 52.4 * & 25.2 * & 16.2 * & 3.53 & 3.54 & 2.11 * \\
\hline $\operatorname{Te} \operatorname{Tr} 400^{\mathrm{d}}$ & 5.38 & 13.2 & 127.8 & 60.2 & 18.3 & 15.2 * & 3.81 & 3.15 & 3.28 \\
\hline Ore10 ${ }^{a}$ & 5.33 & 13.7 & 135.9 & 59.9 & 19.9 & 14.4 & 3.36 & 3.32 & 3.07 \\
\hline Ore $50^{b}$ & 5.33 & 13.5 & 132.6 & 56.0 * & 23.3 * & 15.0 * & 3.25 & 3.29 & 2.43 * \\
\hline Ore $200^{c}$ & 5.33 & 13.6 & 128.7 & 54.8 * & 23.5 * & 15.5 * & 3.53 & 3.32 & 2.33 * \\
\hline Ore $400^{d}$ & $5.44 *$ & 13.6 & 131.1 & 60.8 & 17.6 & $15.6^{*}$ & 3.49 & 3.19 & 3.44 \\
\hline Clo10 a & 5.31 & 13.3 & 135.9 & 60.6 & 19.0 & 14.6 & 3.23 & 3.33 & 3.19 \\
\hline Clo50 b & 5.33 & 13.5 & 133.0 & 60.9 & 18.8 & 14.6 & 3.12 & 3.40 & 3.24 \\
\hline $\mathrm{Clo} 200^{\mathrm{c}}$ & 5.33 & 13.5 & 133.1 & 60.3 & 19.2 & 14.7 * & 3.22 & 3.41 & 3.14 \\
\hline Clo400 d & 5.44 * & 13.9 & 127.2 & 61.8 & $16.4^{*}$ & 15.8 * & 3.46 & 3.22 & 3.77 * \\
\hline $\mathrm{MON}$ & $5.44 *$ & $11.1^{*}$ & 130.0 & 53.9 * & 28.2 * & 12.5 & 3.39 & $2.64 *$ & 1.99 * \\
\hline SEM $^{1}$ & 0.02 & 0.80 & 2.63 & 0.95 & 0.83 & 0.28 & 0.14 & 0.20 & 0.10 \\
\hline CTR & 5.26 & 17.4 & 131.5 & 61.8 & 20.0 & 14.3 & 1.60 & 2.90 & 3.14 \\
\hline Thy10 a & 5.13 & 17.3 & 130.1 & 63.1 & 20.4 & 13.0 & 1.46 & 2.48 & 3.14 \\
\hline Thy50 b & 5.18 & 17.9 & 127.0 & 58.4 * & 24.8 * & 13.3 & 1.49 & 2.59 & 2.37 * \\
\hline Thy200 c & 5.25 & 16.8 & 127.0 & 58.3 * & 26.0 * & 12.2 * & 1.37 & 2.59 & 2.26 * \\
\hline Thy $400^{\mathrm{d}}$ & 5.37 & $14.4^{*}$ & $125.7^{*}$ & 64.9 * & 20.0 & 11.2 * & 1.59 & 2.44 * & 3.30 \\
\hline $\operatorname{Ros} 10^{a}$ & 5.16 & 16.9 & 128.2 & 63.1 & 20.6 & 12.9 & 1.44 & 2.47 & 3.11 \\
\hline $\operatorname{Ros} 50^{b}$ & 5.15 & 17.1 & 128.0 & 63.1 & 20.4 & 12.9 & 1.66 & 2.59 & 3.14 \\
\hline $\operatorname{Ros} 200^{c}$ & 5.31 & 17.2 & 127.1 & 63.7 & 20.6 & 12.3 * & 1.39 & 2.56 & 3.17 \\
\hline $\operatorname{Ros} 400^{\mathrm{d}}$ & 5.31 & 17.4 & 125.3 * & 64.3 * & 20.2 & 11.6 * & 1.49 & 2.85 & 3.30 \\
\hline Sag10 a & 5.22 & 17.4 & 128.2 & 63.7 & 20.0 & 12.4 & 1.37 & 3.28 & 3.11 \\
\hline Sag50 b & 5.19 & 17.3 & 129.3 & 63.7 & 20.4 & 12.3 & 1.37 & 3.31 & 3.14 \\
\hline Sag200 c & 5.13 & 17.4 & 127.5 & 63.7 & 20.8 & 11.8 * & 1.33 & 3.34 & 3.08 \\
\hline Sag $400^{d}$ & 5.16 & 14.5 * & 125.9 * & 60.7 & 22.4 * & 12.9 & 1.43 & 3.16 & 2.72 * \\
\hline MON & 5.24 & 11.3 * & 134.1 & 55.9 * & 25.8 * & 14.6 & 1.73 & 2.84 & 2.20 * \\
\hline $\mathrm{SEM}^{1}$ & 0.05 & 0.71 & 2.00 & 0.71 & 0.44 & 0.70 & 0.14 & 0.16 & 0.08 \\
\hline
\end{tabular}

${ }^{1}$ SEM-standard error of the mean. ${ }^{2}$ BCVFA—Branch-chained VFA. ${ }^{3} \mathrm{~A}: \mathrm{P}-$ Acetate to propionate ratio. ${ }^{*}$ Means within a column differ from control $(p<0.05) .{ }^{\text {a }} 10 \mathrm{mg} / \mathrm{L} .{ }^{\mathrm{b}} 50 \mathrm{mg} / \mathrm{L} .{ }^{\mathrm{c}} 200$ $\mathrm{mg} / \mathrm{L} .{ }^{\mathrm{d}} 400 \mathrm{mg} / \mathrm{L}$. 
Table 3. Effect of different doses of Treatment 1 (T1: 75\% Tea tree, 25\% Thyme), Treatment 2 (T2: 75\% Tea tree, 25\% Clove bud), Tretament 3 (T3: 75\% Tea tree, 25\% Oregano), Treatment 4 (T4; 50\% Tea tree, 50\% Clove bud), Treatment 5 (T5: 50\% Tea tree, 25\% Thyme, 25\% Oregano), Treatment 6 (T6: $50 \%$ Tea tree, 25\% Clove bud, $25 \%$ Thyme) and Monensin (MON) on $\mathrm{pH}$, ammonia-N and total and individual VFA concentrations in vitro fermentation of 10:90 forage to concentrate diet $(n=6)$.

\begin{tabular}{|c|c|c|c|c|c|c|c|c|c|}
\hline Treatment & $\mathrm{pH}$ & $\mathrm{NH}_{3}, \mathrm{mg} / \mathrm{dL}$ & VFA, mM & Acetate, $\%$ & Propionate, \% & Butyrate, \% & Valerate, $\%$ & $\mathrm{BCVFA}^{2}, \mathrm{mM}$ & $\mathrm{A}: \mathrm{P}^{3}$ \\
\hline CTR & 5.33 & 27.5 & 130.8 & 62.0 & 21.0 & 14.0 & 1.08 & 2.47 & 2.94 \\
\hline $\mathrm{T} 1(10)^{\mathrm{a}}$ & 5.32 & 25.2 & 129.1 & 61.5 & 21.3 & 14.3 & 1.05 & 2.54 & 2.91 \\
\hline $\mathrm{T} 1(50)^{\mathrm{b}}$ & 5.30 & 25.2 & 128.2 & 61.2 & 21.3 & 14.7 & 1.10 & 2.41 & 2.87 \\
\hline $\mathrm{T} 1(200)^{\mathrm{c}}$ & 5.30 & 26.5 & 128.6 & $58.6 *$ & $23.6^{*}$ & 14.3 & 1.20 & 2.36 & $2.48 *$ \\
\hline $\mathrm{T} 1(400)^{\mathrm{d}}$ & $5.28+$ & 25.2 & 126.5 & $58.3 *$ & $24.4 *$ & 14.4 & 1.14 & 2.40 & $2.39 *$ \\
\hline MON & $5.29+$ & $25.2 *$ & $123.5+$ & $58.9^{*}$ & $25.9 *$ & $12.2+$ & 1.29 & $2.10 *$ & $2.28 *$ \\
\hline SEM $^{1}$ & 0.01 & 1.34 & 2.70 & 0.68 & 0.53 & 0.51 & 0.09 & 0.05 & 0.09 \\
\hline CTR & 5.38 & 27.0 & 116.9 & 60.1 & 20.8 & 15.4 & 1.24 & 2.64 & 2.89 \\
\hline $\mathrm{T} 2(10)^{\mathrm{a}}$ & 5.39 & 24.9 & 116.7 & 60.1 & 21.5 & 14.6 & 1.30 & 2.69 & 2.82 \\
\hline $\mathrm{T} 2(50)^{\mathrm{b}}$ & 5.36 & 26.3 & 116.3 & 59.6 & 21.5 & 15.6 & 1.19 & 2.58 & 2.80 \\
\hline $\mathrm{T} 2(200)^{\mathrm{c}}$ & 5.38 & 26.1 & 114.6 & 59.6 & 21.7 & 15.0 & 1.38 & 2.60 & $2.75 *$ \\
\hline $\mathrm{T} 2(400)^{\mathrm{d}}$ & 5.37 & 27.0 & 115.0 & $56.9 *$ & $24.2 *$ & 15.4 & 1.36 & 2.59 & $2.36^{*}$ \\
\hline $\mathrm{T} 3(10)^{\mathrm{a}}$ & 5.36 & 27.3 & 115.7 & 60.0 & 20.6 & 15.6 & 1.20 & 2.64 & 2.88 \\
\hline $\mathrm{T} 3(50)^{\mathrm{b}}$ & 5.38 & 26.6 & 116.2 & 59.7 & 21.5 & 15.3 & 1.33 & 2.62 & 2.78 \\
\hline T3 (200) c & 5.36 & 26.0 & 114.9 & 59.3 & 21.5 & 14.8 & 1.16 & 2.59 & 2.81 \\
\hline $\mathrm{T} 3(400)^{\mathrm{d}}$ & 5.37 & 26.7 & 116.5 & $57.3^{*}$ & $24.0 *$ & 15.1 & 1.48 & 2.58 & 2.40 * \\
\hline MON & 5.36 & 22.7 & 114.2 & $57.5^{*}$ & $26.5^{*}$ & $2.03 *$ & 0.98 & $2.29 *$ & 2.17 * \\
\hline SEM $^{1}$ & 0.01 & 1.34 & 2.70 & 0.68 & 0.53 & 0.51 & 0.09 & 0.05 & 0.09 \\
\hline CTR & 5.40 & 24.9 & 126.0 & 63.8 & 18.1 & 14.6 & 1.09 & 2.95 & 3.53 \\
\hline $\mathrm{T} 4(10)^{\mathrm{a}}$ & 5.39 & 25.6 & 127.2 & 62.7 & 19.0 & 14.7 & 1.10 & 3.01 & 3.30 \\
\hline $\mathrm{T} 4(50)^{\mathrm{b}}$ & 5.34 & 25.9 & 127.2 & 62.3 & 19.6 & 14.5 & 1.26 & 3.04 & 3.19 \\
\hline $\mathrm{T} 4(200)^{c}$ & 5.38 & 24.9 & 127.2 & 63.2 & 18.7 & 14.6 & 1.18 & 2.90 & 3.41 \\
\hline $\mathrm{T} 4(400)^{\mathrm{d}}$ & 5.31 & 23.0 & 125.3 & $59.8 *$ & 22.5 * & 14.1 & 1.14 & 3.10 & $2.66^{*}$ \\
\hline $\mathrm{T} 5(10)^{\mathrm{a}}$ & 5.37 & 24.7 & 124.9 & 62.5 & 19.6 & 14.6 & 1.11 & 2.74 & 3.20 \\
\hline T5 (50) b & 5.33 & 25.1 & 127.2 & 63.0 & 18.7 & 14.9 & 1.14 & 2.84 & 3.37 \\
\hline T5 $(200)^{c}$ & 5.38 & 24.2 & 125.6 & $60.2 *$ & $21.9 *$ & 14.1 & 1.28 & 2.98 & $2.75 *$ \\
\hline $\mathrm{T} 5(400)^{\mathrm{d}}$ & 5.35 & 21.4 & 127.2 & $58.8 *$ & $22.7 *$ & 15.2 & 1.20 & 2.93 & 2.60 * \\
\hline T6 (10) ${ }^{\mathrm{a}}$ & 5.41 & 27.6 & 129.2 & 61.6 & 20.6 & 14.9 & 1.22 & 2.28 & 3.02 \\
\hline $\mathrm{T} 6(50)^{\mathrm{b}}$ & 5.37 & 27.7 & 125.9 & 61.1 & 20.8 & 14.1 & 1.20 & 2.37 & 3.05 \\
\hline T6 (200) ${ }^{c}$ & 5.39 & 28.1 & 128.6 & 62.1 & 21.2 & 14.7 & 1.21 & 2.34 & 2.92 \\
\hline $\mathrm{T} 6(400)^{\mathrm{d}}$ & 5.38 & 27.1 & 127.2 & $59.3 *$ & 21.0 & 14.6 & 1.28 & 2.39 & 2.58 \\
\hline MON & 5.37 & $24.1 *$ & $123.5+$ & $59.6 *$ & $25.1 *$ & $12.3+$ & 1.31 & $2.03 *$ & 2.38 * \\
\hline SEM $^{1}$ & 0.01 & 1.12 & 2.70 & 0.90 & 0.69 & 0.48 & 0.10 & 0.08 & 0.13 \\
\hline
\end{tabular}

${ }^{1} \mathrm{SEM}-$ standard error of the mean. ${ }^{2}$ BCVFA—Branch-chained VFA. ${ }^{3}$ A:P-Acetate to propionate ratio. ${ }^{*}$ Means within a column differ from control $(p<0.05) .{ }^{\text {a }} 10 \mathrm{mg} / \mathrm{L} .{ }^{\mathrm{b}} 50 \mathrm{mg} / \mathrm{L} .{ }^{\mathrm{c}} 200$ $\mathrm{mg} / \mathrm{L} .{ }^{\mathrm{d}} 400 \mathrm{mg} / \mathrm{L}$. 


\subsection{Experiment 2 (Combination of Essential Oils)}

Treatments 7 to 13 had no effect on rumen fermentation profile and are not reported. The effects of treatments 1 to 6 are shown in Table 3. Monensin reduced $(p<0.05)$ the molar proportion of acetate, the molar proportion of butyrate, the BCVFA concentrations, the A:P ratio and the concentration of ammonia-N, and increased $(p<0.05)$ the molar proportion of propionate compared with control. At 10 and $50 \mathrm{mg} / \mathrm{L}$, none of the treatments had effects on rumen fermentation profile compared with control.

Treatment 1 at 200 and $400 \mathrm{mg} / \mathrm{L}$ decreased $(p<0.05)$ the molar proportion of acetate $(-5$ to $-6 \%)$ and the A:P ratio $(-16$ to $-19 \%)$, and increased $(p<0.05)$ the molar proportion of propionate $(+12$ to $+16 \%)$. Treatment 1 at $400 \mathrm{mg} / \mathrm{L}$ tended to reduce $(p<0.10)$ the $\mathrm{pH}$ compared with control Treatment 2 only at $400 \mathrm{mg} / \mathrm{L}$ decreased $(p<0.05)$ the molar proportion of acetate $(-5 \%)$ and the A:P ratio $(-18 \%)$, and increased $(p<0.05)$ the propionate proportion $(+16 \%)$ when compared with control. Treatment 3 only at $400 \mathrm{mg} / \mathrm{L}$ decreased $(p<0.05)$ the molar proportion of acetate $(-4 \%)$ and the A:P ratio $(-17 \%)$, and increased $(p<0.05)$ the molar proportion of propionate $(+15 \%)$ compared with control. Treatment $4 \mathrm{had}$ no effect at $200 \mathrm{mg} / \mathrm{L}$ but at $400 \mathrm{mg} / \mathrm{L}$ decreased $(p<0.05)$ the molar proportion of acetate $(-6 \%)$ and the A:P ratio $(-25 \%)$, and increased $(p<0.05)$ the molar proportion of propionate $(+24 \%)$ compared with control. Treatment 5 at 200 and $400 \mathrm{mg} / \mathrm{L}$ decreased $(p<0.05)$ the molar proportion of acetate $(-6$ to $-8 \%)$ and the A:P ratio $(-22$ to $+26 \%)$, and increased $(p<0.05)$ the molar proportion of propionate $(+21$ to $+25 \%$ ) when compared with control. Treatment 6 had no effect at $200 \mathrm{mg} / \mathrm{L}$, and only the molar proportion of acetate decreased $(-5 \% ; p<0.05)$ at $400 \mathrm{mg} / \mathrm{L} \mathrm{compared} \mathrm{with} \mathrm{the} \mathrm{control.}$ When mixes modified rumen microbial fermentation (T1 to T6), the relative effects of the mixes of EO were compared with the closest doses of TeTr oil in Experiment 1, and the size of the effect increased, suggesting no additive or synergistic effects.

\section{Discussion}

In the last two decades, there has been a wealth of data produced by research on the effect of EO on rumen microbial fermentation, most of it in in vitro conditions [1,2]. However, most of it has focused on dairy cattle, where fermentation was conducted in high forage diets at $\mathrm{pH}$ 6.5-7.0. There are few reports on the effects of EO on ruminal microbial fermentation in high concentrate diets fed to feedlot beef cattle $[5,13,14]$. The antimicrobial activity of EO is affected by $\mathrm{pH}$, and ruminal $\mathrm{pH}$ in cattle fed high-concentrate diets is different from that of dairy cattle diets and often below 6.0 [5]. These effects may also affect potential interactions among different EO in mixes. The selection criteria to identify EO with positive effects on rumen microbial fermentation in these conditions were an increase or no change in total VFA, an increase in the proportion of propionate, and/or a decrease in the proportion of acetate, the A:P ratio and/or the ammonia-N concentration. These effects would improve the efficiency of energy and $\mathrm{N}$ utilization [1]. On the other hand, Calsamiglia et al. [1] suggested that, because of different mechanisms of action, the combination of EO may result in additive or synergistic effects. In fact, most EO products in the market are based on combination of different EO or their active molecules (i.e., CRINA-Ruminants ${ }^{\circledR}$, DSM, Switzerland; AGOLIN ${ }^{\circledR}$, Agolin Sa, Switzerland, XTRACT ${ }^{\circledR}$, Pancosma, Switzerland), but scientific evidence of their additive or synergistic effects is lacking.

Monensin has been recognized as an effective in-feed antibiotic that results in an increase in propionate at the expenses of acetate, and reduces amino acid deamination $[15,16]$ and was used as a positive control. The effects of monensin in Experiments 1 and 2 show these effects and confirm the reliability of the method to measure these changes in the selected EO. At similar concentrations as monensin, EO in Experiment 1 and EO mixes in Experiment 2 had no effects on rumen fermentation, even when considering the concentration of active components. This observation indicates that the activity of EO is weaker compared with monensin, and higher doses are required to provoke a change in rumen microbial fermentation. 


\subsection{Experiment 1 (Individual Essential Oils)}

Ammonia-N was only reduced in Thy and Sag at the highest dose, and the magnitude of the reduction was much lower than that observed for monensin. The effect of Thy on ammonia-N concentration agrees with previous reports where Thy was tested in similar conditions and doses [17]. Because Sag had negative effects on VFA and Thy did not affect VFA at the high dose, the effects of EO on ammonia-N could not be considered as a criterion to select EO for Experiment 2.

Thyme and Ore contain high concentrations of thymol and carvacrol as major active components, respectively. Thymol and carvacrol are phenolic monoterpenes with a wide-spectrum antimicrobial activity due to its capacity to act as membrane permeabilizer [18-20]. Juven et al. [21] observed that their antibacterial activity was greater at $\mathrm{pH} 5.5$ compared with the activity at $\mathrm{pH} 6.5$. In the beef-type diet conditions of this experiment, Ore and Thy at 50 and $200 \mathrm{mg} / \mathrm{L}$ were affected in the same way as total and individual VFA, reflecting a similar mechanism of action, and are in agreement with previous results in similar conditions $[5,17]$. The lack or negative effect of these EO up to $500 \mathrm{mg} / \mathrm{L}$ also agrees with previous reports [22,23], but higher doses inhibit rumen microbial fermentation. These results indicate that Ore and Thy should be included at moderate doses to modify rumen fermentation profile without inhibiting microbial activity. Because phenolic compounds with similar structure may have additive effects [6], these two EO were selected for further exploration of possible interactions in Experiment 2.

Terpinen-4-ol is the main active component in TeTr and has a wide-spectrum antimicrobial activity [24]. The TeTr at 50 and $200 \mathrm{mg} / \mathrm{L}$ decreased the molar proportion of acetate and the A:P ratio and increased the molar proportion of propionate and the molar proportion of butyrate, a fermentation profile consistent with better energy utilization [1]. In fact, at $200 \mathrm{mg} / \mathrm{L}$, the effect on the A:P ratio was the largest among all EO tested in Experiment 1. Results agree with Castillejos et al. [22] using similar fermentation conditions and doses. Although some reports have shown negative effects of TeTr on rumen microbial fermentation [25-27], with a significant reduction in total VFA and propionate concentrations, these trials were carried out with ruminal liquid and conditions for dairy cows and at $\mathrm{pH}>6.0$. Several authors have already recognized the role of media $\mathrm{pH}$ and type of diet on the antimicrobial activity of EO [5,21]. Therefore, results obtained in the present report with high concentrate beef-type fermentation conditions justify the selection of $\mathrm{TeTr}$ for further study in Experiment 2.

Clove bud oil at $200 \mathrm{mg} / \mathrm{L}$ increased the molar proportion of butyrate, and at $400 \mathrm{mg} / \mathrm{l}$ decreased the molar proportion of propionate and increased the molar proportion of butyrate, the A:P ratio and the $\mathrm{pH}$ compared with the control. Castillejos et al. [22] also reported that Clo at $500 \mathrm{mg} / \mathrm{L}$ reduced the molar proportion of propionate and increased the molar proportion of butyrate and the A:P ratio. This fermentation profile is not adequate to improve energy utilization in beef cattle diets. In the present trial, Clo at moderate dose (10 and $50 \mathrm{mg} / \mathrm{L}$ ) increased the ammonia- $\mathrm{N}$ concentrations in $1 \%$ and $2 \%$ vs. control, but differences were not significant. In contrast, at lower doses $(30 \mathrm{mg} / \mathrm{L})$, Cardozo et al. [5] reported that eugenol increased total VFA by $20 \%$ and increased the concentration of ammonia-N, which could be desirable if ammonia-N concentration limits microbial protein synthesis in feedlot cattle fed high percentages of concentrate [28].

Rosemary oil only had effects at the highest dose but reduced total VFA concentrations and the proportion of butyrate, and increased the acetate proportion. This fermentation profile is not desirable in beef cattle conditions, where an increase in propionate is desired [1]. Sage oil at the highest dose decreased the A:P ratio, but at the same time total VFA was also reduced, suggesting that microbial fermentation was inhibited. It is interesting to observe that the active components of Ros and Sag are 1,8-cineole and thujone, respectively, and both are oxygenated phenols. Oxygenated phenols have been reported to have negative or even antagonistic effects when mixed with other phenolic compounds [6], and therefore, were discarded for Experiment 2. 


\subsection{Experiment 2 (Combination of Essential Oils)}

In Experiment 1, TeTr, Ore and Thy at 50 and $200 \mathrm{mg} / \mathrm{L}$ had the most appropriate fermentation profile to improve energy utilization in beef cattle diets. The main active components of these EO are phenolic monoterpens. Bassole and Juliani [6] indicated that phenolic compounds tend to have additive effects, while synergistic or antagonistic effects would occur with other chemical compounds and vary depending on the microbial ecosystem. Clove bud oil was selected because previous research suggested that at pH 5.5 and at moderate doses stimulated deamination activity and inhibited peptide lyses [3,5]. Because of the different mechanisms of action involved, synergies may be expected. Furthermore, the main active component, eugenol, is a phenylpropanoid, which may have synergies or antagonistic effects with phenolic monoterpenes [6]. There are no previous reports designed to explore interactions between the selected EO on rumen fermentation profile in beef feedlot-type fermentation conditions.

In Experiment 1, TeTr was the EO with the strongest response at doses of 50 to $200 \mathrm{mg} / \mathrm{L}$. For this reason, most of the mixes proposed contained TeTr at different effective concentrations. Treatments at 200 or $400 \mathrm{mg} / \mathrm{L}$ and with 50 or $75 \%$ of TeTr (corresponding to an effective dose of TeTr of 100 to 300 $\mathrm{mg} / \mathrm{L}$ ) reduced the proportion of acetate and the A:P ratio, and increased the proportion of propionate without affecting the total concentration of VFA (T1 to T5). The effective doses of TeTr in the mixes were within the range of those tested in Experiment 1, and the magnitude of the response was never higher that the effect observed when TeTr oils was supplemented alone in Experiment 1 . Therefore, there is no evidence that the combination of different EO had an additive or synergistic effect neither with monoterpenes, nor with phenolpropanoids. It is also interesting to observe that whenever Ore, Thy or both were mixed with Clo (see T7 to T13, Table 1), the fermentation profile was not affected. In treatments T7 to T13 (Table 1), $100 \mathrm{mg}$ of Thy, Ore or the combination of both resulted in no effect if mixed with 100, 200 or $300 \mathrm{mg}$ of Clo. This is surprising because both Thy and Ore reduced acetate, increase propionate and reduced the A:P ratio when incubated alone in Experiment 1, but this effect was inhibited by the presence of Clo. Treatment T6 contained TeTr, and even in cases where the effective concentration of TeTr was 100 and $200 \mathrm{mg} / \mathrm{L}$ that resulted in improved fermentation profile in Experiment 1, there was only a small reduction in the acetate proportion $(-5 \%)$, no effect on propionate and a non-significant reduction of the A:P ratio. There seem to be an antagonistic effect by which the combination of either Thy, Ore or both with Clo resulted in no effect on rumen fermentation profile.

None of the mixes in Experiment 2 affected ammonia-N concentration or BCVFA, suggesting that deamination was not affected. This is not surprising, because only Thy and Sag at $400 \mathrm{mg}$ in Experiment 1 had effects, and in none of the treatments in Experiment 2 the effective dose of these EO was reached. Clove bud oil was selected because Busquet et al. [27] indicated that it reduced peptide degradation. We hypothesized that the combination of the inhibition of peptide degradation by eugenol in Clo may be synergistic with inhibition of deaminnation shown in Thy. However, the combination of different EO appear no to have this additive or synergistic effect in protein degradation. These results question the common practice of mixing different $\mathrm{EO}$ based on potential additive or synergistic effects.

\section{Conclusions}

Tea tree oil, oregano oil and thyme oil can be effective as rumen fermentation modifiers under feedlot beef-type fermentation conditions. The combinations of TeTr oil with Ore oil, Thy oil or Ore + Thy did not have additive effects over those observed with TeTr oil alone. When Thy, Ore or Thy + Ore where mixed with Clo, all effects on rumen fermentation profile disappeared even when TeTr was part of the mix, suggesting an antagonistic interaction of Clo with Thy and Ore. Results do not support the hypothesis of additivity among the EO tested, and antagonistic effects of Clo mixed with Thy or Ore were demonstrated at least in a low $\mathrm{pH}$, beef-type fermentation conditions.

Author Contributions: Conceptualization, I.F., A.F., D.M., L.C. and S.C.; methodology, I.F., D.M. and S.C.; formal analysis, I.F. and D.M.; resources, S.C. and L.C.; data curation, I.F., G.F.-T. and S.C.; writing-Original draft 
preparation, I.F and G.F.-T.; writing-Review and editing, A.F., D.M., L.C. and S.C.; supervision, S.C.; project administration, S.C. All authors have read and agreed to the published version of the manuscript.

Funding: This research received no external funding.

Conflicts of Interest: The authors declare no conflict of interest.

\section{References}

1. Calsamiglia, S.; Busquet, M.; Cardozo, P.W.; Castillejos, L.; Ferret, A. Invited Review: Essential oils as modifiers of rumen microbial fermentation. J. Anim. Sci. 2007, 90, 2580-2595. [CrossRef]

2. Benchaar, C.; McAllister, T.A.; Chouinard, P.Y. Digestion, ruminal fermentation, ciliate protozoal populations, and milk production from dairy cows fed cinnamaldehyde, quebracho condensed tannin, or Yucca schidigera saponin extracts. J. Dairy Sci. 2008, 91, 4765-4777. [CrossRef]

3. Busquet, M.; Calsamiglia, S.; Ferret, A.; Kamel, C. Screening for effects of plant extracts and active compounds of plants on dairy cattle rumen microbial fermentation in a continuous culture system. Anim. Feed Sci. Technol. 2005, 123-124, 597-613. [CrossRef]

4. Castillejos, L.; Calsamiglia, S.; Ferret, A.; Losa, R. Effects of a specific blend of essential oil compounds and the type of diet on rumen microbial fermentation and nutrient flow from a continuous culture system. Anim. Feed Sci. Technol. 2005, 119, 29-41. [CrossRef]

5. Cardozo, P.W.; Calsamiglia, S.; Ferret, A.; Kamel, C. Screening for the effects of natural plant extracts at different $\mathrm{pH}$ on in vitro rumen microbial fermentation of a high-concentrate diet for beef cattle. J. Anim. Sci. 2005, 83, 2572-2579. [CrossRef]

6. Bassolé, I.H.N.; Juliani, H.R. Essential oils in combination and their antimicrobial properties. Molecules. 2012, 17, 3989-4006. [CrossRef] [PubMed]

7. Hyldgaard, M.; Mygind, T.; Meyer, R.L. Essential oils in food preservation: Mode of action, synergies, and interactions with food matrix components. Front. Microbiol. 2012, 3, 1-24. [CrossRef]

8. $\quad$ Langeveld, W.T.; Veldhuizen, E.J.A.; Burt, S.A. Synergy between essential oil components and antibiotics: A review. Crit. Rev. Microbiol. 2013, 40, 76-94. [CrossRef] [PubMed]

9. NRC. Nutrient Requirements of Beef Cattle, 7th rev. ed; Nat. Acad. Press: AcadWashington DC, USA, 1996.

10. McDougall, E.I. Studies on ruminant saliva. 1. The composition and output of sheep's saliva. Biochem. J. 1948, 43, 99-109. [CrossRef] [PubMed]

11. Chaney, A.L.; Marbach, E.P. Modified reagents for determination of urea and ammonia. Clin. Chem. 1962, 8, 130-132. [PubMed]

12. Jouany, J.P. Volatile fatty acid and alcohol determination in digestive contents, silage juices, bacterial cultures and anaerobic fermentor contents. Sci. Aliment. 1982, 2, 131-144.

13. Benchaar, C.; Duynisveld, J.L.; Charmley, E. Effects of monensin and increasing dose levels of a mixture of essential oil compounds on intake, digestion and growth performance of beef cattle. Can. J. Anim. Sci. 2006, 86, 91-96. [CrossRef]

14. Nanon, A.; Suksombat, W.; Yang, W.Z. Effects of essential oils supplementation on in vitro and in situ feed digestion in beef cattle. Anim. Feed Sci. Technol. 2014, 196, 50-59. [CrossRef]

15. Wallace, R.J.; Czerkawski, J.W.; Breckenridge, G. Effect of monensin on the fermentation of basal rations in the Rumen Simulation Technique (Rusitec). Br. J. Nutr. 1981, 46, 131-148. [CrossRef] [PubMed]

16. Chalupa, W.; Corbett, W.; Brethour, J.R. Effects of monensin and amicloral on rumen fermentation. J. Anim. Sci. 1980, 51, 170-179. [CrossRef] [PubMed]

17. Castillejos, L.; Calsamiglia, S.; Ferret, A. Effect of essential oil active compounds on rumen microbial fermentation and nutrient flow in in vitro systems. J. Dairy Sci. 2006, 89, 2649-2658. [CrossRef]

18. Dorman, H.J.D.; Deans, S.G. Antimicrobial agents from plants: Antibacterial activity of plant volatile oils. J. Appl. Microbiol. 2000, 88, 308-316. [CrossRef] [PubMed]

19. Walsh, S.E.; Maillard, J.Y.; Russell, A.D.; Catrenich, C.E.; Charbonneau, D.L.; Bartolo, R.G. Activity and mechanisms of action of selected biocidal agents on Gram-positive and -negative bacteria. J. Appl. Microbiol. 2003, 94, 240-247. [CrossRef]

20. Lambert, R.J.W.; Skandamis, P.N.; Coote, P.J.; Nychas, G.J.E. A study of the minimum inhibitory concentration and mode of action of oregano essential oil, thymol and carvacrol. J. Appl. Microbiol. 2001, 91, 453-462. [CrossRef] 
21. Juven, B.J.; Kanner, J.; Schved, F.; Weisslowicz, H. Factors that interact with the antibacterial action of thyme essential oil and its active constituents. J. Appl. Bacteriol. 1994, 76, 626-631. [CrossRef]

22. Castillejos, L.; Calsamiglia, S.; Martín-Tereso, J.; Ter Wijlen, H. In vitro evaluation of effects of ten essential oils at three doses on ruminal fermentation of high concentrate feedlot-type diets. Anim. Feed Sci. Technol. 2008, 145, 259-270. [CrossRef]

23. Macheboeuf, D.; Morgavi, D.P.; Papon, Y.; Mousset, J.L.; Arturo-Schaan, M. Dose-response effects of essential oils on in vitro fermentation activity of the rumen microbial population. Anim. Feed Sci. Technol. 2008, 145, 335-350. [CrossRef]

24. Davidson, P.M.; Naidu, A.S. Phyto-phenols. In Natural Food Antimicrobial Systems; CRC Press: Boca Raton, FL, USA, 2000; pp. 265-293.

25. Hristov, A.N.; Ropp, J.K.; Zaman, S.; Melgar, A. Effects of essential oils on in vitro ruminal fermentation and ammonia release. Anim. Feed Sci. Technol. 2008, 144, 55-64. [CrossRef]

26. Gunal, M.; Ishlak, A.; AbuGhazaleh, A.A.; Khattab, W. Essential oils effect on rumen fermentation and biohydrogenation under in vitro conditions. Czech., J. Anim. Sci. 2014, 59, 450-459. [CrossRef]

27. Busquet, M.; Calsamiglia, S.; Ferret, A.; Kamel, C. Plant Extracts Affect In Vitro Rumen Microbial Fermentation. J. Dairy Sci. 2006, 89, 761-771. [CrossRef]

28. Devant, M.; Ferret, A.; Gasa, J.; Calsamiglia, S.; Casals, R. Effects of protein concentration and degradability on performance, ruminal fermentation, and nitrogen metabolism in rapidly growing heifers fed high-concentrate diets from 100 to $230 \mathrm{~kg}$ body weight. J. Anim. Sci. 2000, 78, 1667-1676. [CrossRef]

(C) 2020 by the authors. Licensee MDPI, Basel, Switzerland. This article is an open access article distributed under the terms and conditions of the Creative Commons Attribution (CC BY) license (http://creativecommons.org/licenses/by/4.0/). 